\title{
THE FIRST STEP IN EVALUATING REMOVAL OF ORGANIC COMPOUNDS IN TREATMENT PLANTS FOR MUNICIPAL LEACHATE
}

\author{
Lars Thörneby \\ University of Kalmar, Sweden
}

\section{INTRODUCTION}

When looking for an adequate treatment method for landfill leachate it is important to find a balance between policies and investments. It is possible to remove all pollutant from water if enough money is put in the project and all known treatment methods are applied on a particular water. However, this is not a cost-effective way to go. It is better first, discover what kind of pollutants could be found and had to be removed (this may seem obvious, but we have, until recently, not known enough about organic compounds in leachate to fully assess the problem); second, examine the costs of achieving those goals (here is problems as we, so far, know very little about removal of specific organic compounds in different treatment system); and third, look for the most cost-effective treatment method/methods. It is important that at least the first two steps is fulfilled otherwise there is a risk that investments are made which later on turm out not to have solved the real problem. Thus, money may be spent to reduce one pollutant, when in fact most of the serious pollutants is transported unaffected through the treatment plant. This paper deal with the first step "What is to find in MSW leachate?"

During the past five decades the use of chemicals have dramatically increased. More than 10 million of chemical compounds are identified including both natural and synthetic compounds. About 70,000 of these compounds are obtainable on the market [1]. Most of these compounds are for professionally use. However, 50,000 products registered in National Chemicals Inspectorate products register are classified as hazardous and about 3000 of these products are available for the households for example in products for daily care, cleaning and care of cars [2]. Furthermore environmentally hazardous chemicals are incorporated in furmiture, building material, cars, electronic and electric equipment etc. When out of use much of this were landfilled before we become aware of the negative effects. Even if we today try to sort the waste streams there is always a part, which will be landfilled hence creating an environmental threat from a contaminated leachate.

Besides nutrients, and metals, landfill leachate is shown to contain a wide variety of organic compounds of anthropogenic origin. In a recent investigation of leachate from three Swedish landfills 200 organic compounds was found [3]. Some of these compounds are hazardous and sometimes also persistent. Classes of environmental hazardous compounds found in leachate are Halogenated Hydrocarbons; PHCs 
KALMAR ECO-TECH'03

Bioremediation and Leachate Treatment

KALMAR, SWEDEN, November 25-27, 2003

(Petrogenic Hydrocarbons); PAHs (Polycyclic Aromatic Hydrocarbons) including Naphtalenes; POPs (Persistent Organic Pollutants); Pesticides/ Biocides and Industrial Chemicals (e.g. phthalates, nonylphenols, flame retardants as PBDE and organic phosphates). These types of compounds mostly occur in very low concentrations in leachate, which make them hard to identify and often also hard to detect. Compared to the total organic content in the leachate measured as TOC or COD these compounds represents only a fraction. Furthermore, compounds are decomposed both in the landfill and the following treatment system. The metabolites may sometimes be more hazardous than the original compound and also harder to find. As a consequence of the low concentration and the fact that we mostly do not know what to look for the metabolites is often missed. In MSW leachate there is also natural compounds as volatile fatty acids, esters, alcohols etc. produced by microbial metabolism of organics in the waste.

Due to these difficulties it is understandably that focus so far has been on BOD, TOC, nutrients and metals when characterizing leachate. Naturally, also the treatment performance has, so far, been evaluated by those parameters.

There are several priority lists where hazardous compounds are pointed out. These lists might be helpful in the search for compounds of interest for characterization of leachate and judgment of treatment efficiency. So have the OSPAR Convention several groups of compounds as PAHs, PCBs and SCCP (Short chained chlorinated paraffins) on the priority list and hundreds of compounds on the candidate list [4]. Helsinki Convention has a few dozen compounds [5] and EU Directive for water 2000/60/EC 32 compounds on the priority list [6]. A Swedish list "Example of substances requiring particular attention" called Observation list [7] has been published by Issued by the Swedish National Chemicals Inspectorate in collaboration with the Swedish Environmental Protection Agency and the Swedish National Board of Occupational Safety and Health.

The list of compounds below is not covering all types of compounds found in leachate but deal with some of the most common hazardous compounds found in Swedish leachates. Also, the categories are not fully stringent. Several of the discussed compounds belong to more than one category.

\section{HALOGENATED HYDROCARBONS}

Several halogenated compounds are on the EU priority list for compounds, which use should decrease in order to minimize the risk for spill and discharge to the environment (REF). Examples of such compounds found in leachate and/or in landfill gas are chlorinated alkanes/alkenes as 1,2-Dichloroethane, Dichloromethane, Trichloromethane and chlorinated aromatics as Dichlorobenzenes $[3,8]$ Members of these classes are in the priority lists. Chlorinated paraffins (chlorinated straight chain hydrocarbons) are also found in the priority lists. Chlorinated paraffins are used as plasticisers in PVC and other plastics, extreme pressure lubricant additives, flame-retardants, paint and as sealant additives. Chlorinated paraffins has very high distribution coefficient octanol/water, very low solubility in water and low vapor pressures. Hence, they probably stay in the landfill or if they escape, they are then adsorbed to particles. Due to the large amount of types of chlorinated paraffins they are difficult to detect.. Chlorinated paraffins are relatively 
persistent, bioaccumulative and toxic. They might be found in sludge, filters and in soil from irrigated areas.

\section{PETROGENIC HYDROCARBONS}

PHCs may occur in landfill leachate from landfills receiving sludge from gas stations or waste from remediation sites and waste from other industries using petrochemicals. Infiltration of oily water at the landfill was commonly done in the past and might also be a source of PHC found in leachate. Many PHCs are aliphatic compounds of different chain length and more or less branched. They span from highly volatile as in gasoline to non-volatile HCs in bitumen. However several PHCs are aromatic for example Benzene, Toulene, Ethylbenzene and Xylene. These four aromatics commonly called BTEX indicate pollution of the water from a possible petrogenic source. They are easily detected for example by purge and trap followed by thermal desorption and analysed by gas chromatography, as they all are highly volatile and unpolar. Other compounds of interest are substituted Benzenes as Styrene, Tri-methylbenzenes, Di-ethylbenzenes, Propylbenzenes etc. There is a huge amount of combinations and these aromatics is therefore often collected in groups according to number of additional carbons to a benzene ring: C3-Benzene, C4-Benzene etc. Straight and branched aliphatic hydrocarbons are also to be found in leachate.

\section{POLYCYCLIC AROMATIC HYDROCARBONS}

PAHs including Naphtalens are frequently found in leachate from different types of landfills. Naphtalene and substituted naphtalenes are volatile and are found in landfill gas as well as in leachate. PAHs are used as raw material for synthesis, and as wood preservatives. PAHs are also a component in creosote; in crude oil and are formed by incineration for example at a fire on the landfill.

Anthracene is a PB-substance (Persistent and Bioaccumulating ) Benz[a]anhtracene is carcinogen a PB-substance and toxic for water organisms Benz[b]fluorantene and Benz[j]fluorantene ere carcinogens. Benz[a]pyrene is carcinogen, mutagen and a PBTsubstance (Persistent, Bioaccumulating and Toxic), Phenanthrene, Fluoranthene, Chrysene and Pyrene are all classified as PBT-substances. These PAHs are non-volatile compounds, which easily adsorb to particles. Hence, high levels of suspended solids in the leachate enhance the mobility in the water phase.

\section{PERSISTENT ORGANIC POLLUTANTS (POPS)}

POPs are lipid soluble compounds with low vapour pressures. POPs are also polychlorinated hence they are not or very slowly metabolised which have the result that these compounds biomagnifies These lipid soluble compounds with high Kow values have capabilities of bioaccumulation due to the difficulties for organisms to secret these compounds. Persistent lipid soluble compounds will be magnified in the food chain as they will not be secreted from or decomposed in the organism. Many POPs are classified as vPvB-substances (very Persistent and very Bioaccumulating. 
KALMAR ECO-TECH'03

Bioremediation and Leachate Treatment

KALMAR, SWEDEN, November 25-27, 2003

Polychlorinated biphenyls (PCBs) have some unique qualities. They are very stable, non-combustible and are non-conductive. Hence, has PCB been used in electrical equipment as transformers, capacitors but also, due to its resistance against external influence, in building material as additive to sealant and cement. Due to PCBs stability and the fact that they are bioaccumulating PCBs are banned since the 70's but can still be found in the environment.

\section{PESTICIDES AND BIOCIDES}

In Sweden, about 8000 tonnes (active substance) pesticides and biocides is sold per annum of which 2000 tonnes is herbicides, fungicides and insecticides. Pesticides and biocides found in leachate may come from formerly disposed not emptied containers and packages but may also come today from illicit disposal of forbidden pesticides from households, gardeners and farmers. Modern pesticides are relatively mobile in water phase and will be washed out readily from the waste. Modern pesticides are also more readily metabolised both in water and in soil. Older pesticides had often higher Koc-value and were more persistent will therefore leak slowly from the waste probably at so low concentration that they are impossible to detect in the leachate. Analysis of sludge is a possible way to go to get knowledge if these substances are disposed at the landfill. Phenoxy acids, bentazon, DDD and DDE have been found in Swedish leachates [8]. N,N Dietyltoluamid is an active substance in mosquito repellants has been found in relatively high concentration in leachate from Swedish MSW landfills but also in leachate from a landfill in Indonesia (unpublished results).

\section{PHARMACEUTICALS}

This type of organic compounds is probably a larger problem in wastewater treatment plants than in landfill leachate. However, some pharmaceutical seems to be common in leachate.

Ibuprofen, phenazon and iso-propylphenazon (analgesic-antipyrenic, anti-inflammatory agents) have been found in Swedish leachates [1]. Iso-propylphenazon has previously also been identified by the author in both a Swedish and a Indonesian landfill (unpublished results).

\section{INDUSTRIAL CHEMICALS}

In this group are chemicals of more or less frequent use by both households and industries. Groups of compounds of more or less natural origin found in MSW leachate are alcohols, ethers, ketones, acids, esters, terpenes and terpenoids but also strict anthropogenic compounds as phthalates, brominated flame retardants etc are found in MSW leachate.

\subsection{Terpenes/ Terpenoids}

Terpenes are hydrocarbons of biological origin having carbon skeletons formally derived from isoprene $\left[\mathrm{CH}_{2}=\mathrm{C}\left(\mathrm{CH}_{3}\right) \mathrm{CH}=\mathrm{CH}_{2}\right]$. Terpenes are subdivided into $\mathrm{C}_{5}$ hemiterpenes, $\mathrm{C}_{10}$ monoterpenes, $\mathrm{C}_{15}$ sesquiterpenes, $\mathrm{C}_{20}$ diterpenes, $\mathrm{C}_{25}$ sesterterpenes, $\mathrm{C}_{30}$ triterpenes, 
KALMAR ECO-TECH'03

Bioremediation and Leachate Treatment

KALMAR, SWEDEN, November 25-27, 2003

$\mathrm{C}_{40}$ tetraterpenes (carotenoids) and polyterpenes. Terpenoids are natural products also derived from isoprene units but contain oxygen in various functional groups. This class is subdivided according to the number of carbon atoms in the same manner, as are terpenes. Terpenoids occur in both open chain and cyclic structures (aliphatic alicyclic and aromatic) in almost every possible structural arrangement that gives them great mixture complexity. Terpenes and terpenoids are used as solvents, degreasing agents, raw material for synthesis of other compounds and as flavouring agents.

Turpentine consists of $45-75 \%$ a-pinene (1), 5-30\% b-pinene (2), 2-40\% 3-carene (3), other turpentines such as limonene and camphene and their oxidation products, such as alcohols and aldehydes. It is above all a-pinene that is used for synthesis to camphor, synthetic pine oil, camphene, linalool and many other substances used as odorants and and as raw materials for pharmaceuticals. The limonene fraction is sold as a solvent under the name of Dipentene . Limonene is relatively persistent, biomagnifies and has been found in breast milk. Camphor is used as plasticiser in oils.

\subsection{Phenolic compounds}

Phenol is primarily a man-made chemical, although it is also naturally found in animal wastes and decomposing organic materials. The largest use of phenol is as an intermediate for the production of phenolic resins. Phenol is also used as an intermediate for production synthetic fibres, Phenol is also used as chemical toxic against bacteria and fungi. Substituted phenols as $\mathrm{m} / \mathrm{p}$-Cresol and dimethylphenols are found in MSW leachate. Possible origin is petroleum, coal tars, photo developer, disinfectants, paints or pesticides.

Chlorinated phenols as, for example, 4-Chlorophenol and 4-chloro-3-methylphenol are mostly found in leachate from industrial landfills but sometimes also in MSW leachate. Chlorinated phenols are mainly used for manufacturing of industrial and agricultural products. Sources of chlorinated phenols in leachate might be chlorinated phenoxyacetic acids and preservatives for wood, leather etc.

Two phenols found in leachates are widely used as antioxidant additives Bis-phenol $\mathrm{A}$ and BHT. Bisphenol A (4,4'-isopropylidenediphenol), is frequently used to make epoxy and other resins as antioxidant in plastic and rubber and is for example used paint for inner coating of tins. Bisphenol A is an OSPAR candidate It has oestrogen effects and is a suspect carcinogen. BHT (Butylated hydroxitoluene) is used in large quantities as antioxidant in food and petroleum products. It is also used as antifoam agent, additive to lubrication oil and binder. $\mathrm{vPvB}$ substance When oxidized, BHT is transformed to dienone and further to bis- and polyphenols. Other similar compounds with similar use are TBF (2,6-di-tertbutylfenol), 4-tert-butylphenol (possible estrogenic effects) and 2,4,6tris(1,1-dimethylethyl-)phenol (PBT-substance)

The greater part of all nonylphenol manufactured is used for production of surfactants, above all nonylphenolethoxylate (detergent, emulsifier). Another widely used nonylphenol derivate is tris-(4-nonyl) phosphite, which is now being superseded as a stabiliser in rubber and plastic by more hydrolytically insensitive substances like tris (2,4- 
KALMAR ECO-TECH'03

Bioremediation and Leachate Treatment

KALMAR, SWEDEN, November 25-27, 2003

di-tert-butylphenyl) phosphite. Barium and calcium salts of nonylphenol are used as heat stabilisers in plastic. Phosphate esters of nonylphenol can be used as flame retardant. The substance is also used in binder, e.g. in various alkydes. Nonylphenol and nonylphenolethoxylate is found in leachate from several landfills in Sweden $[1,10]$

\subsection{Phthalates}

A variety of phthalate esters is commonly found in MSW leachate. Phthalates is dominantly used as additive plasticisers in polymers such as plastic and rubber but also in paints and adhesives. As phthalates is not reactively bound, they tend to leak to the environment. Phthalates has also hormone-like effects. The predominating phthalate as plasticicer in polymers is di-(2-ethylhexyl) phthalate (DEHP) which is used in manufacturing of plastics rubber and paper is found in products for flooring, wall hangings, cable, foil and plastic coated fabrics, toys, insecticides, liquid soap, washing detergents, ink, industrial oils, film and cosmetics. Benzylbutyl phthalate (BBP) is specially used for production of foamed PVC, which is mainly used as a flooring material and in cars. Di-methyl phthalate) is used in manufacturing of plastics and rubber and as solvents for example in perfumes and pesticides. Diethyl phthalate (DEP) is used as plasticiser in polymers. DEP is found in toothbrushes, cars, tools, food packages, insecticides, pharmaceuticals, cosmetics, washing detergents, aftershave and skin lotion. Dibutyl phthalate (DBP) is mainly used in manufacturing of polymers but is also found in nail varnish, mosquito repellants, perfume, ink and is also used for textile coating. Dioctyl phthalate (DOP) is found in plastics, rubber and film An other occasionally found phthalate is $\mathrm{Di}(2$-etylbutyl) phthalate (DEBP).

Due to the common use of phthalates in daily used products and phthalates are ubiquitous laboratory contaminants precautions must be taken when analysing phthalates. All solvents and chemicals must be checked for phthalate contamination. Phthalates is hydrolysed at $\mathrm{pH}$ below 5 and at $\mathrm{pH}$ above 7 and has a tendency to adsorb to glassware, which also make analysis more difficult. Liquid-Liquid-Extraction followed by GC-ECD or GC-MS is a common analysis procedure [9].

\subsection{Organic phosphates}

Organic phosphate esters may be found in relatively high concentrations in leachate from industrial landfills but also, to a lesser extent, in MSW leachate. Organic phosphate esters are used as flame-retardants, plasticisers and as anti-wear additives. As organic phosphates are not chemichally bonded to the bulk material it can easily evaporate and hence be found in the nearby environment [10].

Dimethyl methylphosphonate is used as flame retardant, additive to solvents and gasoline, as conditioning and antistatic treatment of textiles. Tris(2-chloroethyl)phosphate have been used in polyurethane foam. Today it is used as an additive to polyvinyl acetate for surface treatment of textiles and furniture textiles. It is also used in flame resistant paints. Tris(1-chloro-2-propyl)phosphate (TCCP) is mainly used in polyurethane foam in furniture upholstering. TCCP is also used as flame retardant in polyester gel coat and in transparent walls and roofs. TCCP is relatively persistent. Tris(1,3-dichloro-2-propyl) 
KALMAR ECO-TECH'03

Bioremediation and Leachate Treatment

KALMAR, SWEDEN, November 25-27, 2003

phosphate (TDCPP) is used as additive flame retardant in polyurethane foam, polyisocyanate foam and in many other polymers and resins. It is also used for surface treatment of textiles. TDCPP is found in leachate. Tris(2,3-dichloropropyl) phosphate is used as flame retardant and as a secondary plasticiser. Tricresyl phosphate (TCP) is used as plasticiser in PVC (mainly in cars), as flame retardant in plastics, as a solvent for nitrocellulose and in hydraulic fluids.

\subsection{Brominated flame retardants}

Hexabromobenzene (HBB) is used as flame retardant in polymers. HBB is volatile and a suspect P-substance. Polybrominated biphenyls (PBB) is similar to PCBs (chlorine changed to bromide). They are volatile and persistent and have same chemical properties as PCBs. PBBs are used as flame-retardants in polymers.

Polybrominated flame-retardants (PBDE) are used as additive flame-retardants in furnitures (polystyrene, polyurethane foam), textiles, electronic equipment (wire and cable insulation and electrical connectors). Decabromodiphenyl ether (DeBDE) is the most important commercial product of PBDEs followed by Pentabromodihenyl ether (PeBDE) and Octabromodiphenyl ether (OBDE). Tetrabromophenyl ethers (TeBDEs) is a part of commercial PeBDE. PBDEs are PB substance persistent and bioaccumulate. TeBDEs and PeBDEs has been found in human breast milk. Tetrabromobisphenol A (TBBPA) is per volume the largest flame retardant in the world. TBBPA is used as an additive in many plastics as ABS, polystyrene and phenol resins. TBBPA is relatively persistent, bioaccumulate and probably biomagnifies.

Focus has recently been set on the substances in this group and they are being investigated very thoroughly at present; e.g. Chemosphere vol. 46, 2000, is a special issue devoted to brominated flame-retardants.

Brominated flame-retardants have high adsorption coefficients to organic matter, which make it unlikely to find them in leachate in detectable amounts. It is more likely to find PBDEs in sediment, in filters and in soil irrigated by leachate.

\subsection{Silanes/Siloxanes}

Silanes and siloxanes found in leachates are formed as methylation products in landfills (non-cyclic compounds) or due to cyclisation reaction from disposed silica-containing wastes (silicones, silicon oils, additive, shampoos, skin creams, toothpaste, production of food etc.) [11].

Found species in Leachate are the following: Trimethylsilanol, Tri-methoxy-methyl silane, tetra-methoxy silane, hexamethyl disiloxane, hexamethyl cyclotrisiloxane, octamethyl cyclotetrasiloxane, decamethyl cyclopentasiloxane, dodecamethylpentasiloxane. 


\section{REFERENCES}

[1] Lönngren 1992) Lönngren, R., 1992: Intemational approaches to Chemicals control. A historical overview., The National Chemicals Inspectorate, Sweden.

[2] Bucht, B. och Lindh, T., 1994, Kemikalietillsyn i leverantörsledet, Rapport från Kemikalieinspektionen, nr. 4/94.

[3] Paxéus N. (2000) Organic compounds in municipal landfill leachates, Water Science and Technology Vol 42 Nos 7-8 pp 323-333

[4] OSPAR commission for the protection of the marine environment of the north-east Atlantic. Action plan update 2000. Priority Chemicals in Annex 2. http://www.ospar.org

[5] HELCOM, Helsinki Commission, The Baltic Marine Environment protection Commission. Harmful substances. ttp://www.helcom.fi/convention/annex92.html

[6] EU, Europeiska gemenskapens kommission. Ändrat förslag till Europaparlamentets och rådets beslut om upprättande av en lista över prioriterade ämnen på vattenpolitikens område. 2000/0035 (COD) Bryssel den 16.1.2001 KOM(2001)slutlig. http://europa.eu.int/eur-lex/pri/en/oj/dat/2001/ce154/ce15420010529en01170122.pdf

[7] OBS-listan, http://www.kemi.se/raw/documents/18287_OBS98.pdfExempellista över ämnen som kräver särskild uppmärksamhet

[8] Öman C. and Hynning P-Å., (1993), Identification of organic compounds in municipal landfill leachate, Environmental Pollution,80, 265-271.

[9] US EPA 8061A, Phthalate esters by gas chromatography with electron capture detection (GC/ECD) http://www.usepa.gov

[10] Haglund, P. (2000) Fosforbaserade flamskyddsmedel - behov av screening av halter i Svensk miljö? Rapport till Miljöövervakningen, Naturvårdsverket. Found at: http://www.environ.se/dokument/mo/modok/export/fosflam.pdf

[11] Schweigkofler Meand Niessner R., Determination of Siloxanes and VOC in Landfill Gas and Sewage Gas by Canister Sampling and GC-MS/AES Analysis Environ. Sci. Technol. 1999, 33, 3680-3685 